\title{
Treatment of refractory juvenile dermatomyositis with tacrolimus
}

\author{
Jihaan Hassan • Jan Jaap van der Net • \\ Annet van Royen-Kerkhof
}

Received: 26 May 2008 /Revised: 5 July 2008 / Accepted: 7 July 2008 / Published online: 21 August 2008

(C) The Author(s) 2008

\begin{abstract}
We report the clinical course of three patients with refractory juvenile dermatomyositis (JDM) who were treated with tacrolimus. All three children had extensive skin disease and severe muscle weakness and were corticosteroid dependent. All three patients showed impressive improvement of mainly the cutaneous lesions. Furthermore, overall disease activity decreased, all children became more physically active, and corticosteroid treatment could be tapered. However, none of the patients showed recovery of muscle strength, which was most likely due to irreversible muscle damage related to the long-standing myositis and/or highdose steroid treatment. Patients were followed up for 7 to 9 months after the introduction of tacrolimus. No adverse effects were seen. These cases demonstrate that tacrolimus has beneficial effects in children with refractory JDM, especially in those with severe cutaneous manifestations.
\end{abstract}

Keywords Juvenile dermatomyositis · Tacrolimus

\section{Introduction}

Juvenile dermatomyositis (JDM) is the most common of the paediatric inflammatory myopathies and is characterised by

J. Hassan · A. van Royen-Kerkhof $(\bowtie)$

Department of Pediatric Immunology and Rheumatology,

Wilhelmina Children's Hospital,

University Medical Centre Utrecht,

Room KC 03.063.0, Lundlaan 6,

3584 EA Utrecht, The Netherlands

e-mail: a.vanroyen@umcutrecht.nl

J. Hassan · J. J. van der Net

Department of Paediatric Physiotherapy \& Exercise Physiology,

Wilhelmina Children's Hospital,

University Medical Centre Utrecht,

Utrecht, The Netherlands proximal muscle weakness and rash. Corticosteroids are the treatment of choice and have dramatically reduced morbidity and mortality rates in the past decades [1]. Second-line agents used to treat steroid-resistant disease or to induce steroidsparing effect in children include methotrexate (MTX), intravenous immunoglobulins (IVIG), cyclophosphamide, cyclosporine A, hydrochloroquine, mycophenolate mofetil (MMF), rituximab and TNF-alpha antagonists [1]. Tacrolimus, an inhibitor of T-cell activation and proliferation, is one of the new therapeutic options for JDM. Little is known about its efficacy in this patient group.

Therefore, the goal of this case report is to describe our experiences with tacrolimus in JDM patients. We present three children with refractory JDM who showed positive responses to oral tacrolimus.

\section{Case reports}

Case 1

A 6-year-old boy was diagnosed with JDM in December 2002. Treatment was started with prednisolone $2 \mathrm{mg} \mathrm{kg}^{-1}$ day ${ }^{-1}$. Substantial improvement of the severe muscle weakness was not achieved until after additional treatment with MTX, intravenous IVIG and rituximab in the 3 months following admission. In the following years, relapses occurred despite the medication and were treated with methylprednisolone pulse therapy and IVIG. MTX was switched to MMF, and hydrochloroquine was added. Muscle strength remained stable in this period. Childhood Myositis Assessment Scale (CMAS) score was between 36 and 40 (maximum score 52). In September 2006, recurrence of severe myositis, accompanied by dysphagia and vasculitis of the skin, led to prolonged admission. Increase of the steroid dose and administration of 
rituximab did not improve his condition. The patient became dependent on nightly oxygen, most likely due to respiratory muscle weakness. Starting December 2006, monthly doses of cyclophosphamide were given. Nevertheless, a relapse occurred in April 2007, with predominant involvement of the skin. In July/August 2007, the patient had developed gastrointestinal manifestations of the dermatomyositis which responded well to methylprednisolone pulse therapy. There was diffuse erythema of the face and extremities, and the serum muscle enzyme levels were elevated. Therefore, the decision was made to introduce oral tacrolimus (target serum level $10 \mu \mathrm{g} / \mathrm{l}$, therapeutic range $5-15 \mu \mathrm{g} / \mathrm{l})$. Three weeks after starting tacrolimus, the patient had become more physically active, the skin lesions started to resolve, and muscle enzyme levels normalized. In the 7 months of follow-up, the patient was able to walk greater distances, the cutaneous manifestations showed impressive improvement with only very mild erythema in the face, and the prednisolone was tapered down to $0.1 \mathrm{mg} \mathrm{kg}^{-1} \mathrm{day}^{-1}$ without any signs of exacerbation. However, muscle weakness persisted (CMAS 36-38) and was attributed to permanent muscle damage caused by the myostis and steroid treatment. No adverse effects of the tacrolimus were observed.

\section{Case 2}

A 6-year old girl was diagnosed with JDM in February 2007 after a 10-month history of progressive proximal muscle weakness. During the prolonged admission that followed, the patient was first treated with methylprednisolone pulse therapy, followed by oral prednisone $2 \mathrm{mg} \mathrm{kg}^{-1} \mathrm{day}^{-1}$ and MTX. Due to further loss of muscle strength, cyclophosphamide and rituximab were administered. Still, she suffered from severe myalgia, had a CMAS score of 4 and was bedridden. She also had extensive skin lesions in the face, trunk and legs, and the muscle enzymes remained elevated. Consequently, tacrolimus was initiated in June 2007 while prednisolone $\left(0.8 \mathrm{mg} \mathrm{kg}^{-1}\right.$ day $\left.^{-1}\right)$ and MTX $\left(20 \mathrm{mg} \mathrm{m}^{-2}\right.$ week $^{-1}$ s.c. $)$ were continued. Improvement started to show 2 to 3 weeks after initiation of tacrolimus treatment. There was no myalgia, and the patient was increasingly mobile, although there was still severe muscle weakness with a CMAS score of 10 and muscle contractures in the lower extremities that severely impaired further ambulation. Skin involvement was significantly reduced, and the serum muscle enzyme levels decreased gradually. In the following 4 weeks, she participated more in daily activities, and the skin lesion continued to improve. No side effects of the tacrolimus were seen in the 9 months of follow-up. Because of the severity of the disease activity, after reaching remission status with tacrolimus, autologous bone marrow transplantation was performed.
Case 3

A 4-year-old girl was diagnosed as having JDM in March 2003. She initially responded to treatment with prednisolone $2 \mathrm{mg} \mathrm{kg}^{-1}$ day $^{-1}$ and IVIG. However, she relapsed during tapering of the prednisolone. Steroid pulse therapy, MTX and IVIG were needed to control disease activity. In the second half of 2004, increased muscle weakness, vasculitis of the skin and extensive calcifications that first started in the lower extremities and later involved the upper extremities were observed. A new course of IVIG did not improve the skin involvement. Subsequently, rituximab was given to stabilise disease activity and taper down the prednisolone. However, tapering of the steroids again led to increased myositis and skin activity. As the patient was becoming increasingly impaired in daily activities despite additional treatment with MMF (1 g/day) and hydrochloroquine, tacrolimus was introduced in July 2007. At that time, muscle enzyme levels were within normal range, and CMAS score was 28. Two weeks later, improvement of the skin disease was observed. In the following 8 months, most of the cutaneous lesions disappeared, the patient became more energetic and was even able to run again. The prednisolone dose was reduced to $0.15 \mathrm{mg} \mathrm{kg}^{-1} \mathrm{day}^{-1}$. No side effects of the tacrolimus were observed.

\section{Discussion}

Tacrolimus is a calcineurin inhibitor that suppresses the IL-2dependant T-cell activation [2]. It is widely used in transplant medicine and has been shown to be effective in several autoimmune diseases including rheumatoid arthritis, systemic lupus erythematosus and inflammatory bowel disease [3-5]. Beneficial effects of tacrolimus have also been demonstrated in adult polymyositis and dermatomyositis [6-10]. Little is known about the efficacy of systemic tacrolimus in juvenile dermatomyositis. There have been three case reports on this topic [11-13]. Yamada et al. reported a 13-year-old girl with steroid-dependant JDM who was previously treated with MTX, azathioprine, IVIG and cyclosporine A [11] and showed significant improvement only after introduction of tacrolimus. Three other children were described by Modesto et al. [12]. After 1 year of tacrolimus treatment, muscle strength normalised in all three patients, skin abnormalities resolved completely in two children and improved substantially in the third and steroid treatment could be discontinued in two children, while the dose was tapered in the third. Finally, in a report of six children, who were given tacrolimus for 1 year, Martin Nalda et al. showed significant improvement of both muscle strength and skin disease [13]. 
The three case descriptions presented in the current report also suggest beneficial effects of tacrolimus treatment. All three patients had extensive vasculitis of the skin and severe muscle weakness. The skin lesions improved greatly in all patients but did not resolve completely during the follow-up period of 7 to 9 months. The myositis also seemed to respond to the tacrolimus, as muscle enzyme levels normalised in patients 1 and 2, and the myalgia disappeared in patient 2 . However, we did not see any improvement of muscle strength. This could be explained by the prolonged disease course and/ or high-dose corticosteroid treatment that might have caused irreversible muscle damage or the relatively short follow-up period after controlling the disease with tacrolimus, which may not have allowed the muscles to sufficiently restore their strength. It should be noted that, despite the persisting muscle weakness, all patients indicated feeling more energetic and had become more physically active during treatment with tacrolimus. Furthermore, it was possible to effectively reduce the steroid dose in patients 1 (from 0.6 to $0.1 \mathrm{mg} \mathrm{kg}^{-1}$ day $^{-1}$ ) and 3 (from 0.3 to $0.15 \mathrm{mg} \mathrm{kg}^{-1}$ day $^{-1}$ ). This steroid-sparing effect could be explained by the finding that tacrolimus inhibits steroid exporters and increases the hormone-binding function of the glucocorticosteroid receptor [14].

The most common side effects of tacrolimus are concentration-dependant and include gastrointestinal symptoms, hypertension, nefrotoxicity, neurotoxicity, disturbances in glucose metabolism, hyperkalaemia, tremor, headache and sleeping disorders [2]. No adverse effects were observed in our patients. This is in line with findings from previous case reports that showed tacrolimus to be safe after a follow-up period of 1 to 2 years [11-13].

In conclusion, this case report indicates that tacrolimus can substantially improve the cutaneous manifestations of JDM. When administered in an early phase, muscle weakness may improve as well. Therefore, tacrolimus should be considered in JDM cases that are refractory to other immunosuppressive medication.

\section{Disclosures None.}

Open Access This article is distributed under the terms of the Creative Commons Attribution Noncommercial License which per- mits any noncommercial use, distribution, and reproduction in any medium, provided the original author(s) and source are credited.

\section{References}

1. Stringer E, Feldman BM (2006) Advances in the treatment of juvenile dermatomyositis. Curr Opin Rheumatol 18:503-506

2. Wallemacq PE, Verbeeck RK (2001) Comparative clinical pharmacokinetics of tacrolimus in paediatric and adult patients. Clin Pharmacokinet 40:283-295

3. Yocum DE, Furst DE, Kaine JL et al (2003) Efficacy and safety of tacrolimus in patients with rheumatoid arthritis: a double-blind trial. Arthritis Rheum 48:3328-3337

4. Duddridge M, Powell RJ (1997) Treatment of severe and difficult cases of systemic lupus erythematosus with tacrolimus. A report of three cases. Ann Rheum Dis 56:690-692

5. Baumgart DC, Pintoffl JP, Sturm A et al (2006) Tacrolimus is safe and effective in patients with severe steroid-refractory or steroiddependent inflammatory bowel disease - a long-term follow-up. Am J Gastroenterol 101:1048-1056

6. Oddis CV, Sciurba FC, Elmagd KA, Starzl TE (1999) Tacrolimus in refractory polymyositis with interstitial lung disease. Lancet 353:1762-1763

7. Wilkes MR, Sereika SM, Fertig N et al (2005) Treatment of antisynthetase-associated interstitial lung disease with tacrolimus. Arthritis Rheum 52:2439-2446

8. Shimojima Y, Gono T, Yamamoto K et al (2004) Efficacy of tacrolimus in treatment of polymyositis associated with myasthenia gravis. Clin Rheumatol 23:262-265

9. Ochi S, Nanki T, Takada K et al (2005) Favorable outcomes with tacrolimus in two patients with refractory interstitial lung disease associated with polymyositis/dermatomyositis. Clin Exp Rheumatol 23:707-710

10. Mitsui T, Kuroda Y, Kunishige M, Matsumoto T (2005) Successful treatment with tacrolimus in a case of refractory dermatomyositis. Intern Med 44:1197-1179

11. Yamada A, Ohshima Y, Omata N et al (2004) Steroid-sparing effect of tacrolimus in a patient with juvenile dermatomyositis presenting poor bioavailability of cyclosporine A. Eur J Pediatr 163:561-562

12. Modesto C, Boronat M, Marsal S, Arnal-Guimera C (2003) FK506 in the treatment of unresponsive juvenile dermatomyositis. Ann Rheum Dis 59:727-729

13. Martin NA, Modesto CC, Arnal GC et al (2006) Efficacy of tacrolimus (FK-506) in the treatment of recalcitrant juvenile dermatomyositis: study of 6 cases. Med Clin (Barc) 127:697701

14. Davies TH, Ning YM, Sanchez ER (2005) Differential control of glucocorticoid receptor hormone-binding function by tetratricopeptide repeat (TPR) proteins and the immunosuppressive ligand FK506. Biochemistry 44:2030-2038 